tion of elementary and secondary education. The all-too realistic fear in the United States that the economic competition with Japan (and even Europe) will eventually be lost stems from the acknowledged poverty of public education. Should not universities and other institutions of higher education recognize that their survival will even more literally turn on the future health of elementary and secondary education?

But what can research and higher education accomplish in such foreign fields? If it were that the problems of public education in the United States could be solved by spending money, it would probably be a better investment in the future to scrap the Superconducting Super Collider, or the extra shuttle flights, or even the National Science Foundation's doubled budget, for the sake of the improvement that those funds might buy. But money by itself is not sufficient. The more urgent needs are for a better understanding of how schools function well, for a school curriculum which is at once stimulating and improving, for a general appreciation of the particular importance of the most elementary education and for plain speaking about the seriousness of the difficulties created by the continuing impoverishment of the school system. Who but those in the academic community can do all these things? And how can they be neglected when it is as plain as at present in the United States that sufficient attention paid to public education would solve many of the other problems preoccupying the new president?

\section{Fraud on the agenda}

The US Institute of Medicine recommends how malpractice in research should be controlled.

LAST week's report (see page 588) from the Institute of Medicine in the United States is one of the first by an academy or society representing a substantial part of the research community anywhere to face up to the problems of misconduct in the practice of research. That is not nearly as reprehensible as it may seem. Although the past decade has been peppered with lurid accounts of how apparently diligent researchers have pulled wool over the eyes of colleagues, either by the downright fabrication of data or by plagiarism, it is natural that leaders of the research profession should have been slow to respond.

Something akin to charity first prompts the belief that isolated scandals have been made conspicuous by contrast with the general practice, which is honourable. Then follows the proper fear that formal inquiry will engender the general opinion that research is shot through with malpractice. In the circumstances, the Institute of Medicine has been courageous in breaking new ground with its investigation. It is forgivable that its conclusions should be as tentative as they are.

The underlying difficulty is, of course, familiar - that there is no way of telling how common malpractice may be. Banks may hope to fix upper limits on the extent of embezzlement by careful accounting practice, for their losses on this account must always be less than the funds they cannot account for, but there is no arithmetical yardstick by which the total volume of scientific discovery is conserved. So may not the publicized cases of outright misconduct be simply the tip of a much larger iceberg? While there is no means by which the magnitude of the problem can be assessed, that suspicion cannot be flatly denied. What that, in turn, implies is that the damage done to the reputation of the research profession is certain to be much greater than is just. Researchers should not be too indignant on that score; even the most honest stockbrokers have been given a rough time because of the cases of insider trading brought to light in the past few years. The research profession naturally has an interest in regaining its reputation. A little reflection should show that its paymasters, usually governments, should be similarly inclined. How is that to be accomplished? Last week's report points to several ways which are none the worse for being obvious.

Universities should be more diligent and vigorous in their investigation of complaints or even suspicions, as should be grant-making institutions, while journals and professional societies also have their parts to play. Inevitably, the report muses on the incentives for misconduct and, concluding that competition in research and the pressure to publish are in part responsible, asks that something be done to blunt the edges of these pressures. Nothing much is new; the novelty is that it has been said by a respected but independent research academy. But the outcome is not a recipe for what should now be done.

Yet everybody working in research must know the answer. First, research is a profession whose integrity is, by definition, of astounding integrity; if it were otherwise, so that all published data and calculations were suspect, the notion that people can see further than others, in Newton's simile, by standing on the shoulders of others (giants or otherwise) would be falsified, and the scientific enterprise would long since have ground to a halt.

The torrent of discovery in the past few decades is in itself a proof of the integrity of the fabric of science. That is what nervous politicians must be made to understand. But, second, precisely because of the general appreciation of the integrity of the research profession, it is natural that people whose inclinations are less honourable should be attracted to it. In research, the problem is further magnified by unavoidable competition and by the circumstance that people are not required to behave well towards each other. Then, third, because discovery is the process of coming to grips with what people do not understand, mistakes are unavoidable and frequent - and cannot always be unambiguously distinguished from malpractice.

These sociological observations, however trite, have a bearing on the problem the Institute of Medicine (for one) would like to solve - that of minimizing the incidence of malpractice. The first conclusion must be that the incidence can never be absolutely zero, and that attempts to make it so can only bring science to a halt. Second, the people best placed to tell when observations have been improperly carried out or described are the close colleagues and competitors of the author or authors. That no doubt explains why committees of inquiry in this field have had such a poor track record in the past few years.

University departments or their equivalents in other kinds of organizations are better placed to sense when things have gone awry, and to take remedial action quickly. That they have been less effective than might have been expected in the past few years reflects two uncomfortable tendencies - the growing importance of the principal investigator as an autonomous unit in the conduct of research, and the dominance of his relationship with an external source of funds over that with more immediate and discerning colleagues. While principal investigators as such have not been conspicuous among malpractitioners - more often, it has been the hands they hired - putting back that clock completely would be impracticable, and probably unwise. But there is a case for arranging that principal investigators should more often than at present be less dependent on an external grant-making agency, and more dependent on their colleagues locally. At worst, good researchers who are not good managers might be helped to deal perceptively with their assistants.

The Institute of Medicine's report follows most other lines of argument than this. There should be more guidelines, university officials with special responsibility for "the responsible conduct of research", a special office at the National Institutes of Health (and presumably other agencies) to investigate complaints and even courses of instruction for beginners in research. In reality, there is at least as strong a case for believing that grant-making agencies should be less, not more, immediately involved: they should rather confine themselves to making sure that grantrecipients' institutions arrange that their funds are spent responsibly. And most grant-making institutions in the United States are too close to Congress, and too remote from where the action is, to function effectively and quickly in the prevention of misconduct. The best they can hope to do is to function judicially, after the event, which is a heavy-handed business. 